\title{
Facilitation of Monosynaptic and Complex PSPs in Type I Interneurons of Conditioned Hermissenda
}

\author{
Terry Crow and Lian-Ming Tian \\ Department of Neurobiology and Anatomy, University of Texas Medical School, Houston, Texas 77225
}

Synaptic plasticity and intrinsic changes in neuronal excitability are two mechanisms for Pavlovian conditioning. Pavlovian conditioning of Hermissenda produces synaptic facilitation of monosynaptic medial B-medial A IPSPs and intrinsic changes in excitability of type A and $B$ cells in isolated and intact sensory neurons of the conditioned stimulus (CS) pathway. Recently two types of interneurons that receive either excitatory or inhibitory monosynaptic or polysynaptic input from photoreceptors have been identified. On the basis of morphological and electrophysiological criteria, the interneurons have been classified as type $I_{e}, I_{i}$ (direct), and type $I_{e}, I_{i}$ (indirect). We have now examined synaptic facilitation of monosynaptic PSPs in type $I_{e}$ and $I_{i}$ interneurons after conditioning and pseudoran- dom control procedures. Here we report that CS-elicited spike activity is increased in type $\mathrm{I}_{\mathrm{e}}$ interneurons and decreased in type $I_{i}$ interneurons of conditioned animals relative to their respective baseline activity and pseudorandom control groups. Classical conditioning resulted in synaptic facilitation of type $\mathrm{I}_{\mathrm{e}}$ and $\mathrm{I}_{i}$ monosynaptic PSPs elicited by lateral $B$ spikes and enhancement of the amplitude of complex PSPs elicited by the CS. These results provide additional sites of plasticity in the neural circuit involved with the expression of learned behavior produced by Pavlovian conditioning of Hermissenda.

Key words: Hermissenda; Pavlovian conditioning; synaptic facilitation; intrinsic excitability; interneuron plasticity; associative learning
Synaptic plasticity has been a major focus of studies investigating potential mechanisms underlying Pavlovian conditioning (for review, see Beggs et al., 1999). However, there are numerous examples of intrinsic changes in neuronal excitability that can be detected in both mammals and invertebrates after Pavlovian conditioning procedures (Woody and Engel, 1972; Woody et al., 1976; Disterhoft et al., 1986; Moyer et al., 1996; Thompson et al., 1996) (for invertebrate review, see Sahley and Crow, 1998).

Conditioned Hermissenda express both enhanced excitability and synaptic facilitation in the pathway supporting the CS (Crow and Alkon, 1980; Alkon et al., 1982, 1985; Farley and Alkon, 1982; Crow, 1985, 1988; Goh et al., 1985; Matzel et al., 1990; Frysztak and Crow, 1993, 1994, 1997; Gandhi and Matzel, 2000). Pavlovian conditioning of Hermissenda produces conditioned stimulus (CS)-elicited foot shortening and CS-elicited suppression of locomotion (Crow and Alkon, 1978; Lederhendler et al., 1986). Enhanced excitability in identified neurons of conditioned Hermissenda is expressed by an increase in spike activity elicited by the CS or extrinsic current, an increase in the input resistance of type B photoreceptors, decreased spike frequency accommodation, an alteration in the amplitude of light-induced generator potentials, and a reduction in the peak amplitude of voltagedependent $\left(I_{\mathrm{A}}, I_{\mathrm{Ca}}\right)$ and $\mathrm{Ca}^{2+}$-dependent $\left(I_{\mathrm{K}, \mathrm{Ca}}\right)$ currents (Crow and Alkon, 1980; Alkon et al., 1982, 1985; Farley and Alkon, 1982; West et al., 1982; Crow, 1985; Collin et al., 1988; Frysztak and Crow, 1993).

Facilitation of the amplitude of monosynaptic IPSPs in identified photoreceptors has been observed in conditioned Hermis-

\footnotetext{
Received April 11, 2002; revised June 14, 2002; accepted June 19, 2002.

This research was supported by National Institutes of Health Grant MH-58698. We thank Diana Parker for assistance with this manuscript.

Correspondence should be addressed to T. Crow, Department of Neurobiology and Anatomy, P.O. Box 20708, University of Texas Medical School, Houston, TX 77225. E-mail: terry.crow@uth.tmc.edu.

Copyright (C) 2002 Society for Neuroscience $0270-6474 / 02 / 227818-07 \$ 15.00 / 0$
}

senda (Frysztak and Crow, 1994, 1997; Gandhi and Matzel, 2000). Moreover, 5-HT and GABA, two putative neurotransmitters in the unconditioned stimulus (US) pathway, produce synaptic facilitation of type B to type A monosynaptic IPSPs (Schuman and Clark, 1994; Schultz and Clark, 1995). Studies of signal transduction pathways have shown that protein kinase C (PKC) (Farley and Auerbach, 1986; Matzel et al., 1990; Crow et al., 1991; Farley and Schuman, 1991; Frysztak and Crow, 1997; Muzzio et al., 2001) and extracellular signal-regulated protein kinase (Crow et al., 1998) are activated by one-trial and multi-trial Pavlovian conditioning.

To date, the major focus of studies of mechanisms of Pavlovian conditioning in Hermissenda has been the photoreceptors, because the sensory neurons were the first to be identified as sites of plasticity (Crow and Alkon, 1980), and little was known regarding the circuitry supporting the generation of conditioned behavior. More recently, two types of interneurons in the CS pathway have been identified, and their projections to other regions of the CNS have been described (Crow and Tian, 2000, 2002).

Here we report synaptic facilitation of the monosynaptic connection between lateral type $B$ photoreceptors and type $I_{e}$ and $I_{i}$ interneurons of conditioned animals. Type $\mathrm{I}_{\mathrm{e}}$ interneurons expressed an increase in CS-evoked spike activity, enhancement of complex EPSP amplitude, and facilitation of monosynaptic EPSPs evoked by single, type B photoreceptor spikes. Type $\mathrm{I}_{\mathrm{i}}$ interneurons exhibited a facilitation of spike-elicited monosynaptic IPSPs and CS-evoked complex IPSPs in conditioned animals as compared with pseudorandom controls.

\section{MATERIALS AND METHODS}

Animals. Adult Hermissenda crassicornis were used in the experiments. The animals were obtained from Sea Life Supply (Sand City, CA) and maintained in closed artificial seawater (ASW) aquaria at $14 \pm 1^{\circ} \mathrm{C}$ on a $12 \mathrm{hr}$ light/dark cycle. Behavioral training, testing, and electrophysiolog- 
ical procedures were performed during the light phase of the light/dark cycle.

Baseline test of phototactic behavior. The details of the conditioning procedure and methods for testing phototactic behavior have been described in detail in previous publications (Crow and Alkon, 1978; Crow and Offenbach, 1983; Crow, 1985) and will be described only briefly in this report. Animals were tested before training to determine baseline latencies to initiate locomotion in response to a test light. Animals that did not respond within a $20 \mathrm{~min}$ criterion period during the pretraining measurements were not used in the conditioning experiments. Previous research has shown that the increase in the time taken by the animals to locomote into a test light can be accounted for by an increase in the latency to initiate locomotion (Crow and Offenbach, 1983). Animals were placed into 228-mm-long glass tubes filled with artificial seawater. A foam plug inserted through an opening confined the animal to one end of the tube. The tubes were attached by spring clips to a modified turntable enclosed in an incubator maintained at $15^{\circ} \mathrm{C}$. Animals were dark adapted for 12 min before phototactic behavior was tested. A light spot $\left(10^{-4}\right.$ watts $/ \mathrm{cm}^{2}$, white light) was projected onto the center of the turntable, illuminating a circular area $15-16 \mathrm{~cm}$ in diameter. The elapsed times to initiate locomotion in the presence of the test light were recorded when a Hermissenda moved between an infrared emitter and a phototransistor located at the starting end of each glass tube. When the infrared beam was interrupted, a free-running digital clock was turned off, and the time was recorded for later data analysis.

Conditioning procedure. After baseline testing, animals were randomly assigned to the conditioned group or pseudorandom control group. The conditioning phase consisted of 50 trials of the $10 \mathrm{sec}$ CS (light) paired with the US (high speed rotation) (mean interspike interval $=2.5 \mathrm{~min}$ presented each day for 2 consecutive days. The intensity of the CS was the same as the test light used to establish baseline responding for phototactic behavior during the pretest condition. The pseudorandom control group received a total of 100 trials of the CS and US (50 trials each day for 2 consecutive days), each programmed to occur randomly with respect to time and each other with the restriction that the CS and US could not overlap.

Post-acquisition test. All animals received behavioral testing identical to the pretraining (baseline) test measurement for phototaxis $24 \mathrm{hr}$ after the second conditioning session. Animals that did not initiate locomotion in the presence of the CS within 20 min during the post-test received a maximum latency score. Assessment of conditioning was determined by computing suppression ratios that compared post-training phototactic behavior with pretraining test scores. The ratio is expressed as $(A / A+$ $B$ ), where $A$ represents pretraining scores and $B$ represents post-training scores. Conditioned animals exhibited behavioral suppression that was similar in magnitude to previous reports (Crow and Alkon, 1978; Crow and Offenbach, 1983; Crow, 1985). After post-acquisition testing, all animals were coded so that the collection of electrophysiological data was conducted using completely blind experimental procedures.

Intracellular recordings. Intracellular recordings from identified lateral type B photoreceptors and type I interneurons were collected from isolated nervous systems. Anatomical and electrophysiological criteria were used to identify lateral B photoreceptors within the eyes as described previously (Alkon and Fuortes, 1972; Frysztak and Crow, 1994). The type I interneurons were localized to a region of the cerebropleural ganglion as noted in previous publications (Akaike and Alkon, 1980; Crow and Tian, 2000, 2002). For simultaneous recordings from photoreceptors and interneurons, the isolated nervous systems were incubated in a protease solution (Sigma type VIII; $0.67 \mathrm{mg} / \mathrm{ml}, 5 \mathrm{~min}$ ) and rinsed with ASW before the surgical desheathing of a small area of the cerebropleural ganglion to expose the cell bodies of type I interneurons. Type I interneurons were identified on the basis of soma size, cell layer, location in the cerebropleural ganglion, light-elicited complex PSPs, and monosynaptic PSPs evoked by stimulation of identified photoreceptors.

The desheathed circumesophageal nervous systems were pinned to a silicone elastomer (Sylgard, Dow Chemical) stage in a recording chamber filled with ASW of the following composition (in mM): $460 \mathrm{NaCl}, 10 \mathrm{KCl}$, $10 \mathrm{CaCl}_{2}, 55 \mathrm{MgCl}_{2}$, buffered with $10 \mathrm{~mm} \mathrm{HEPES}$ and brought to $\mathrm{pH}$ 7.46 with dilute $\mathrm{NaOH}$. The ASW in the recording chamber was monitored by a thermistor and held at $15 \pm 0.5^{\circ} \mathrm{C}$. CS illumination of the eyes was provided by a tungsten halogen incandescent lamp attached to a fiber optic bundle mounted underneath the recording chamber. For simultaneous recordings, identified pairs of lateral B photoreceptors and type I interneurons were impaled with microelectrodes filled with $4 \mathrm{M} \mathrm{KAc}$ and connected to the two head stages of an Axoclamp 2A (Axon Instruments,

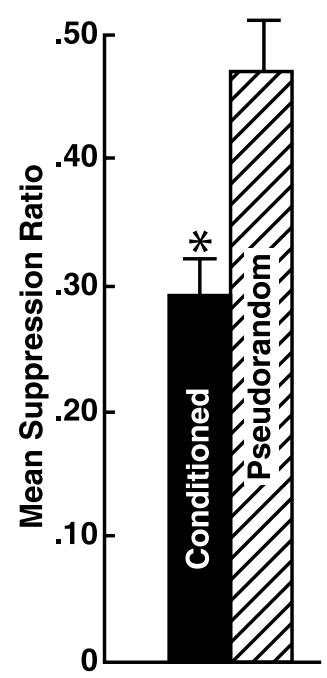

Figure 1. Mean suppression ratios \pm SEM for conditioned $(n=64)$ and pseudorandom controls $(n=54)$. Conditioning produced statistically significant suppression of phototactic behavior compared with pseudorandom controls $\left({ }^{*} p<0.001\right)$.

Foster City, CA). Electrode resistances varied between 60 and $90 \mathrm{M} \Omega$. Standard intracellular recording and stimulation techniques were used. Electrophysiological data were collected on both videotape (Vetter Instruments) and a Gould chart recorder. Taped data were digitized and analyzed using Spike 2 software (Cambridge Electronic Design). Single spikes in identified lateral B photoreceptors were elicited by brief extrinsic current pulses applied in the dark. Evidence for monosynaptic connections between photoreceptors and interneurons was provided by PSPs with relatively constant latencies and a one-for-one relationship between photoreceptor action potentials and PSPs as described previously (Crow and Tian, 2000, 2002). For some experiments, the type $I_{e}$ interneurons were hyperpolarized to approximately $-80 \mathrm{mV}$ to block spike generation during the presentation of the CS, and the complex EPSP was recorded. Effects involving more than two groups were assessed with an ANOVA. Two-group comparisons involved $t$ tests for independent groups.

\section{RESULTS}

\section{Conditioned phototactic suppression}

A total of 118 animals were used in the experiments. The total for the conditioned groups was 64 animals, and 54 animals served as pseudorandom controls. All animals were tested $24 \mathrm{hr}$ after conditioning followed by isolation of the nervous system and collection of electrophysiological recordings from identified type I interneurons or simultaneous recordings from pairs of lateral B photoreceptors and type I interneurons. The mean suppression ratios for the conditioned animals and pseudorandom controls are shown in Figure 1. The statistical analysis showed that 100 conditioning trials produced significant behavioral suppression $(\bar{X}=$ $0.29 \pm 0.03)$ as compared with the group that received 100 pseudorandom presentations of the CS and US $(\bar{X}=0.47 \pm 0.04)$ $\left(t_{116}=4.3 ; p<0.001\right)$.

\section{CS-elicited increase in spike frequency of type $\mathrm{I}_{\mathrm{e}}$ interneurons}

We have reported previously that identified A and B photoreceptors project to two aggregates of type I interneurons; one group is excited (type $I_{e}$ ) and the other inhibited (type $I_{i}$ ) by photoreceptor spikes (Crow and Tian, 2000). We initiated our analysis of Pavlovian conditioning on interneurons by examining CS-elicited changes in spike frequency in type $I_{e}$ interneurons and type $I_{i}$ interneurons from conditioned animals and pseudorandom controls. To assess potential changes in spontaneous activity pro- 
A

Figure 2. Example of the CS-elicited increase in spike frequency for conditioned and pseudorandom controls. CS elicited depolarization and increased spike activity recorded in a type $\mathrm{I}_{\mathrm{e}}$ interneuron from a conditioned animal $(A)$ and pseudorandom control $(B)$. The bar beneath the recordings indicates the presentation of the $10 \mathrm{sec}$ CS. $C$, Group data depicting the mean increase, relative to the $10 \mathrm{sec}$ pre-CS baseline activity, in spike frequency elicited by the CS recorded from type $I_{e}$ interneurons from conditioned and pseudorandom controls. ${ }^{*} p<0.025$.

\section{Conditioned}
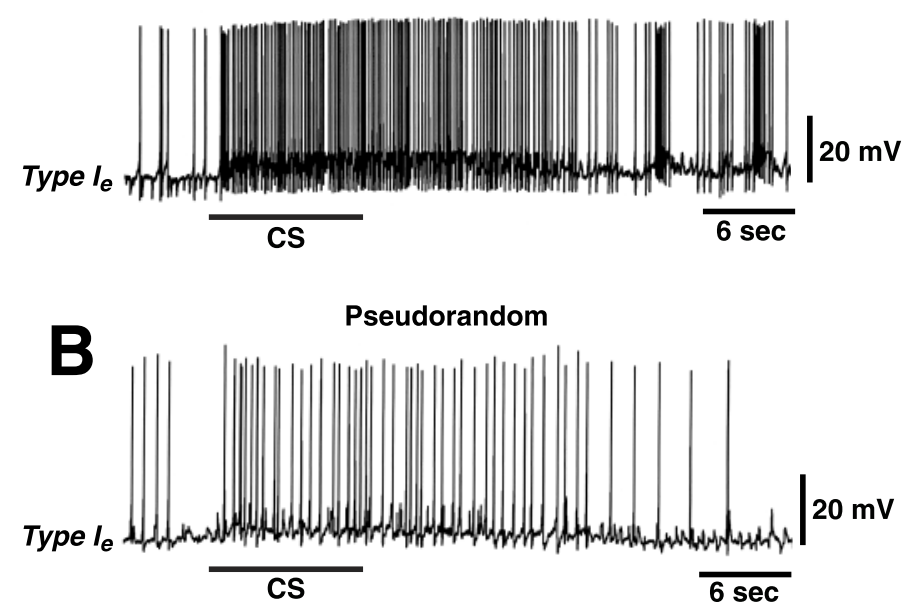

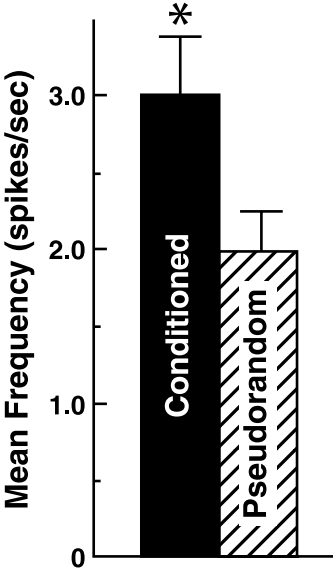

duced by conditioning, we examined spike activity in a $10 \mathrm{sec}$ period immediately preceding the presentation of the CS. The results of the overall statistical analysis revealed no significant differences in spontaneous activity for type $I_{e}$ or type $I_{i}$ interneurons from the conditioned group or pseudorandom controls $\left(F_{(3,100)}=0.72 ; \mathrm{NS}\right)$. Planned two-group comparisons of baseline spike activity between type $\mathrm{I}_{\mathrm{i}}$ interneurons from conditioned and pseudorandom controls were also not significant $\left(t_{35}=0.76\right.$; NS). Comparisons of baseline spike activity between type $I_{e}$ interneurons from conditioned and pseudorandom controls were also consistent with the overall analysis $\left(t_{65}=0.72 ; \mathrm{NS}\right)$ as were comparisons in baseline spike activity between type $I_{i}$ and $I_{e}$ interneurons of conditioned animals $\left(t_{55}=1.08\right.$; NS) and pseudorandom controls $\left(t_{48}=0.66 ; \mathrm{NS}\right)$. These results show that conditioning does not alter the spontaneous spike activity of type I interneurons.

As shown in the examples in Figure 2, the CS elicited more spikes in the type $\mathrm{I}_{\mathrm{e}}$ interneuron from the conditioned preparation (Fig. $2 A$ ) as compared with the pseudorandom control (Fig. $2 B$ ). The mean CS-elicited increase in spike frequency above the baseline computed from the spontaneous activity during a $10 \mathrm{sec}$ period immediately preceding the CS presentation was $3.1 \pm 0.4$ for the conditioned group $(n=16)$ and $2.04 \pm 0.3$ for the pseudorandom controls $(n=20)$ (Fig. $2 C)$. The statistical analysis revealed a significant difference in CS-elicited spike frequency of type $\mathrm{I}_{\mathrm{e}}$ interneurons between conditioned preparations and pseudorandom controls $\left(t_{34}=2.4 ; p<0.025\right)$. The results showed that conditioning produced an increase in CS-elicited spike activity in type $I_{e}$ interneurons.

\section{Enhancement of $\mathrm{I}_{\mathbf{e}}$ complex EPSPs}

The changes in synaptic input to type $I_{e}$ interneurons after conditioning were examined by briefly hyperpolarizing the $I_{e}$ interneurons to block action potentials and recording the complex EPSP elicited by the CS (Fig. 3). Representative examples of CS-elicited complex EPSPs recorded from $\mathrm{I}_{\mathrm{e}}$ interneurons are shown for a conditioned preparation (Fig. $3 A$ ) and a pseudorandom control (Fig. 3B). The CS elicited a larger amplitude complex EPSP with an increased frequency of PSPs in the example from the conditioned preparation (Fig. $3 A, C$ ) as compared with the pseudorandom control (Fig. $3 B, D$ ). The mean peak amplitude of the complex EPSP recorded from conditioned animals
( $n=11)$ was $28.5 \mathrm{mV} \pm 3.4$ and $18.4 \mathrm{mV} \pm 2.1$ for the pseudorandom control $(n=11)$ (Fig. $3 E)$. The difference in peak complex EPSP amplitude between conditioned and pseudorandom controls was statistically significant $\left(t_{20}=2.5 ; p<0.01\right)$.

\section{Enhancement of $\mathbf{I}_{\mathbf{i}}$ complex IPSPs}

We examined the amplitude of CS-elicited complex IPSPs in type $\mathrm{I}_{\mathrm{i}}$ interneurons and found that Pavlovian conditioning resulted in an enhancement of the peak amplitude of the complex IPSP elicited by the CS (Fig. 4). Representative examples of CSelicited complex IPSPs recorded from $\mathrm{I}_{\mathrm{i}}$ interneurons are shown for a conditioned preparation (Fig. $4 A$ ) and a pseudorandom control (Fig. 4B). The group data depicting the average peak amplitude of complex IPSPs for the conditioned and control preparations are shown in Figure $4 C$. The mean amplitude of the complex IPSP recorded from conditioned animals $(n=18)$ was $10.9 \mathrm{mV} \pm 1.0$ and $6.9 \pm 0.9$ for the pseudorandom controls $(n=$ 12). The results of the statistical analysis showed a significant difference in peak amplitude of complex IPSPs between conditioned and pseudorandom controls $\left(t_{28}=2.6 ; p<0.01\right)$.

\section{CS-elicited decrease in spike frequency of type $\mathbf{I}_{\mathbf{i}}$ interneurons}

The effectiveness of the CS in inhibiting spike activity of type $\mathrm{I}_{\mathrm{i}}$ interneurons was examined by determining the number of spikes in type $\mathrm{I}_{\mathrm{i}}$ interneurons generated during the CS presentation (Fig. 4A). As shown in the group data in Figure $4 D$, the presentation of the CS produced a greater decrease in spike activity relative to the $10 \mathrm{sec}$ pre-CS baseline for inhibitory type $I_{i}$ interneurons from conditioned animals $(n=18)(\bar{X}=84.7 \pm$ $4.6 \%)$ as compared with pseudorandom controls $(\bar{X}=39.7 \pm$ $8.8 \%)(n=13)\left(t_{29}=4.9 ; p<0.001\right)$. As would be expected by the finding of enhancement in the amplitude of complex IPSPs in type $I_{i}$ interneurons, the CS was more effective in inhibiting activity in type $I_{i}$ interneurons in conditioned animals relative to pseudorandom controls.

\section{Input resistance of type I interneurons}

The enhancement of the amplitude of complex PSPs detected in type I interneurons of conditioned animals could be produced by presynaptic mechanisms. However, the increase in complex PSP amplitude could also be caused by postsynaptic mechanisms such 


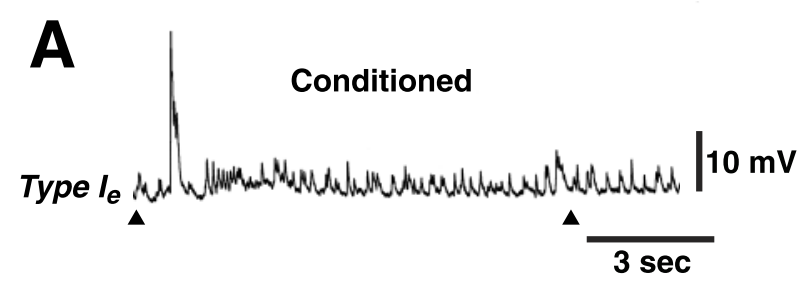

B
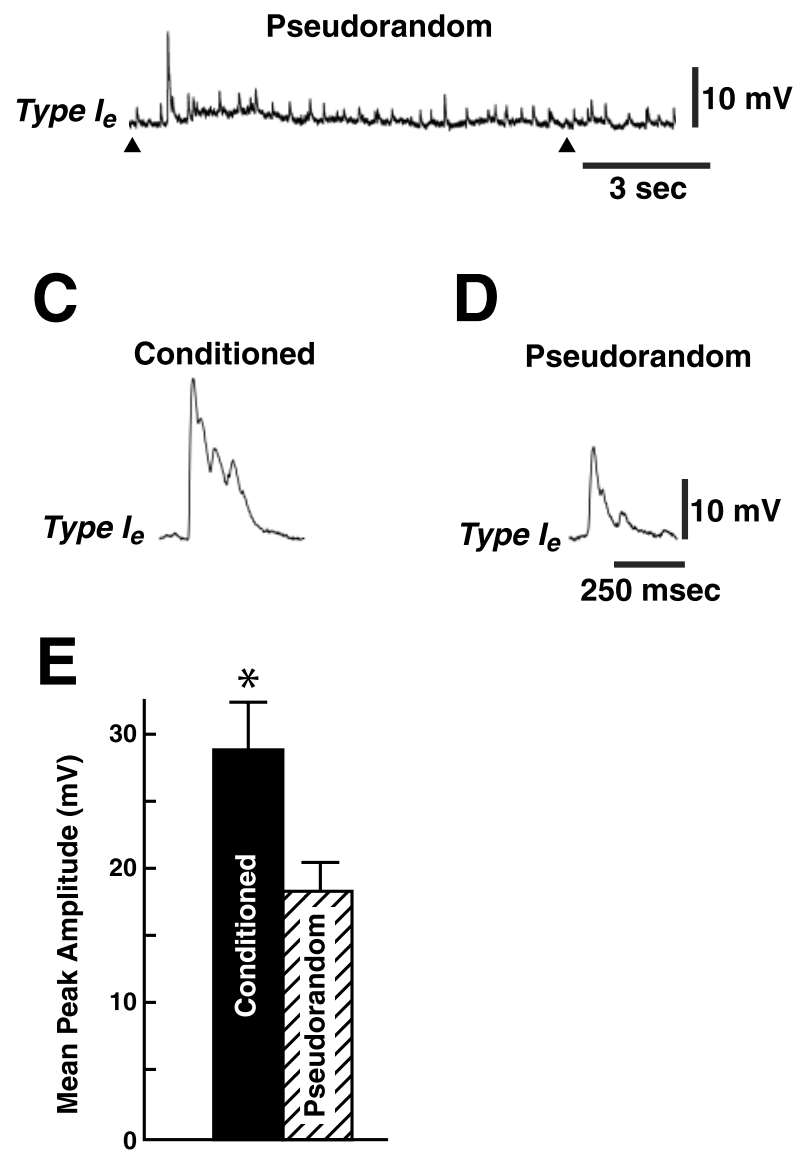

$250 \mathrm{msec}$

Figure 3. Conditioning enhances CS-elicited complex EPSP amplitude. CS-elicited complex EPSP produced from a type $\mathrm{I}_{\mathrm{e}}$ interneuron from a conditioned animal $(A)$ and a pseudorandom control $(B)$. The arrowhead beneath each recording indicates the onset and offset of the $10 \mathrm{sec}$ CS. In these experiments the $I_{e}$ interneurons were briefly hyperpolarized to approximately $-80 \mathrm{mV}$ to block spike activity during the presentation of the CS. The initial component of the complex EPSP is shown on a faster time base in $C$ and $D$. E, Group data depicting the mean ( \pm SEM) peak amplitude of the complex EPSPs recorded from $I_{e}$ interneurons in the conditioned group and pseudorandom controls. ${ }^{*} p<0.01$.

as a modification of intrinsic membrane conductances of type I interneurons. Therefore, a potential postsynaptic contribution to PSP enhancement may be expressed by an increase in the input resistance of type I interneurons. We examined this possibility by measuring the input resistance of type I interneurons from conditioned and pseudorandom controls using brief extrinsic hyperpolarizing current pulses at three levels $(0.1,0.2,0.3 \mathrm{nA})$. No differences in input resistance between $I_{i}$ and $I_{e}$ interneurons from conditioned and pseudorandom controls were detected, so the groups were combined for the overall statistical comparison. Figure 5 insets show three superimposed electrotonic potentials elicited by hyperpolarizing current pulses from a holding poten-
A
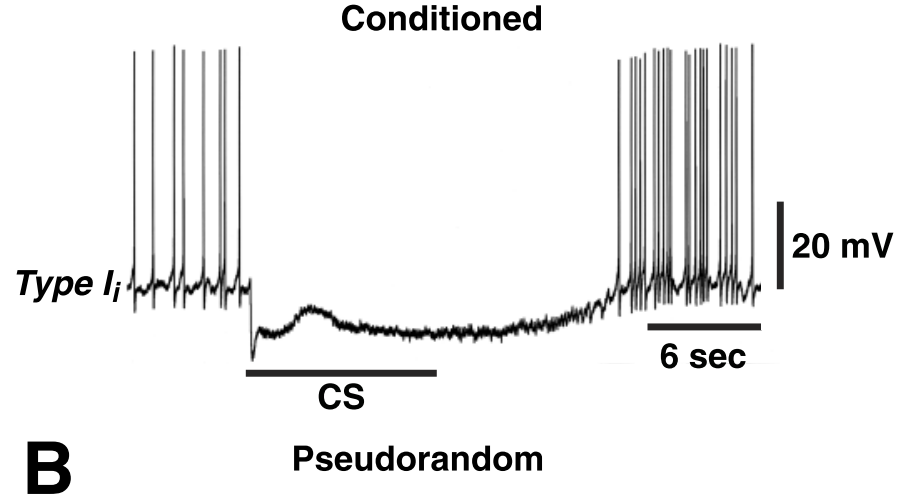

Pseudorandom
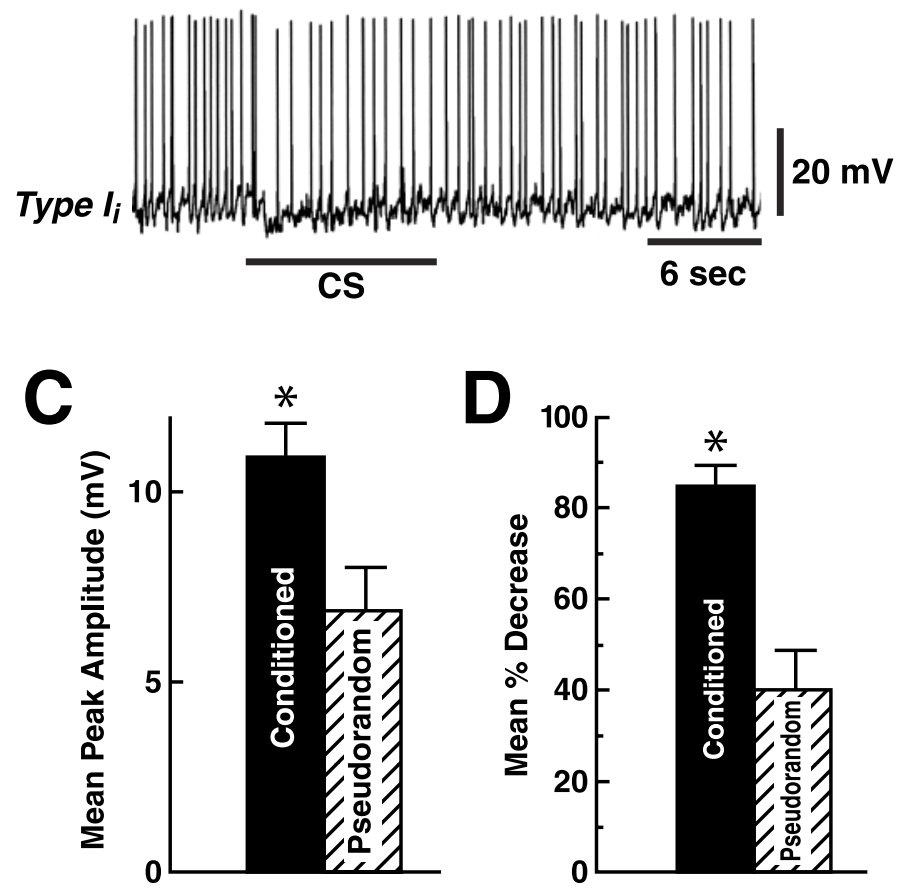

Figure 4. Complex IPSP amplitude elicited by the CS is enhanced in conditioned animals. CS-elicited complex IPSP recorded from a type $\mathrm{I}_{\mathrm{i}}$ interneuron from a conditioned animal $(A)$ and an example from a pseudorandom control $(B)$. The bar beneath the recordings indicates the presentation of the $10 \mathrm{sec} C$ S. The CS evoked a larger amplitude complex IPSP and greater inhibition of spike activity in the conditioned group $(A)$ relative to controls $(B)$. $C$, Group data (means \pm SEM) for the peak amplitude of the complex IPSPs recorded from type $I_{i}$ interneurons from the conditioned group and pseudorandom controls. $D$, Group data depicting the mean percentage decrease in spike activity recorded during the presentation of the CS relative to the pre-CS $10 \mathrm{sec}$ period for the conditioned group and pseudorandom controls. ${ }^{*} p<0.01$ for $C$ and ${ }^{*} p<$ 0.001 for $D$.

tial of $-60 \mathrm{mV}$ collected from an $\mathrm{I}_{\mathrm{i}}$ interneuron in a conditioned preparation (bottom) and an $I_{i}$ interneuron in a pseudorandom control (top). The slope of the $I-V$ plots for the two examples shown in Figure 5 were almost identical. Examining $R_{\text {in }}$ for all of the cells studied from the two groups revealed a mean $R_{\text {in }}$ for all type I interneurons from conditioned animals of $117.9 \pm 3.8 \mathrm{M} \Omega$ and $115.2 \pm 3.7 \mathrm{M} \Omega$ for the pseudorandom controls. The modest difference between the two groups was not statistically significant $\left(t_{60}=1.01 ; \mathrm{NS}\right)$. These results suggest that the enhancement of the amplitude of complex PSPs by conditioning is not likely the result of changes in the input resistance of type I interneurons 
0.3

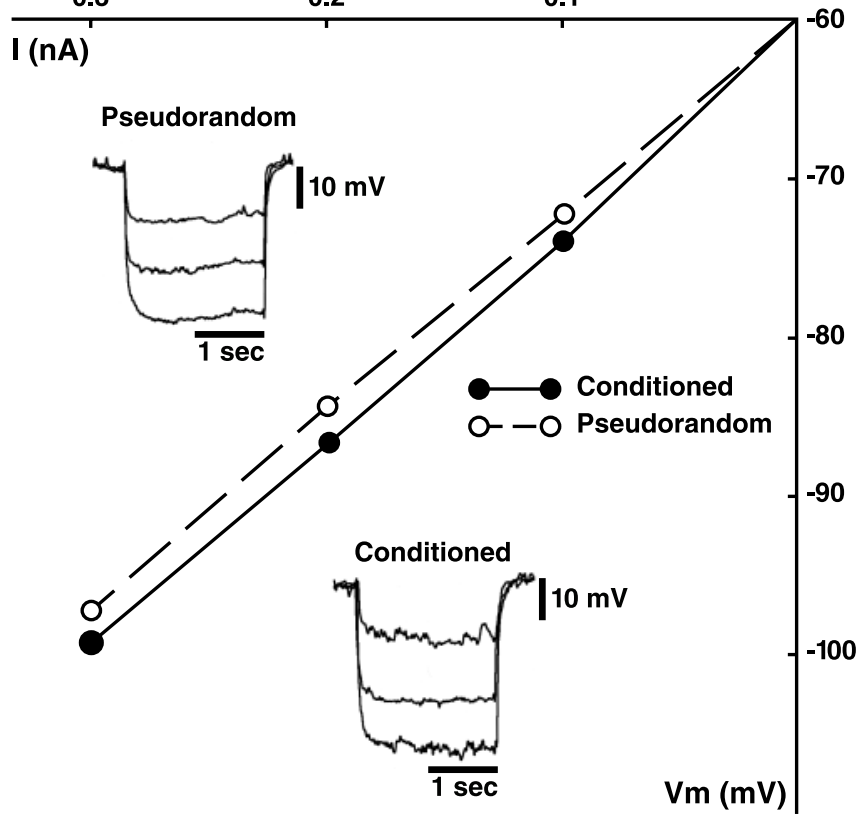

Figure 5. Current-voltage plot for a type $\mathrm{I}_{\mathrm{i}}$ interneuron from a conditioned and pseudorandom control preparation. Insets show three superimposed electrotonic potentials elicited by hyperpolarizing current pulses of increasing magnitude $(0.1,0.2,0.3 \mathrm{nA})$ from a holding potential of -60 $\mathrm{mV}$ for an example from a conditioned preparation (bottom traces) and pseudorandom control (top traces). The slopes of the two $I-V$ plots were similar.

that can be detected at potentials more negative than $-60 \mathrm{mV}$. However, changes in $R_{\text {in }}$ of $\mathrm{I}_{\mathrm{e}}$ interneurons detected at potentials more positive than the holding potential $(-60 \mathrm{mV})$ could contribute to the CS-elicited increase in spike frequency of type $\mathrm{I}_{\mathrm{e}}$ interneurons observed after conditioning. We did not examine $R_{\text {in }}$ at more positive potentials because of problems with accurately measuring the amplitude of electrotonic potentials during spike generation.

\section{Synaptic facilitation of $\mathrm{I}_{\mathrm{e}}$ monosynaptic EPSPs}

We examined changes in the monosynaptic component of the $I_{e}$ interneuron synaptic input by eliciting single spikes in lateral type B photoreceptors and recording monosynaptic EPSPs from $I_{e}$ interneurons. The dark-adapted membrane potential of type $\mathrm{I}_{\mathrm{e}}$ interneurons from conditioned groups $(\bar{X}=49.8 \pm 0.99 \mathrm{mV})$ was not significantly different from pseudorandom controls $(\bar{X}=$ $50.2 \pm 1.1 \mathrm{mV})\left(t_{43}=0.29 ; \mathrm{NS}\right)$. Figure 6 shows representative examples of $\mathrm{I}_{\mathrm{e}}$ interneuron monosynaptic EPSPs elicited by a single lateral B spike from a conditioned animal (A2) and pseudorandom control (B2). The photoreceptors were briefly hyperpolarized to block spontaneous spike activity, and the membrane potential of $I_{e}$ interneurons was held at $-60 \mathrm{mV}$. As shown in the examples in Figure 6, conditioning resulted in a facilitation of the B spike-elicited monosynaptic EPSP amplitude in the $\mathrm{I}_{\mathrm{e}}$ interneuron as compared with the pseudorandom control. The analysis of the group data for the amplitude of monosynaptic EPSPs from conditioned animals $(n=6)$ and pseudorandom controls $(n=6)$ revealed that conditioning produced a significant facilitation of EPSP amplitude $\left(t_{10}=1.97 ; p<0.05\right)$. The summary data showing mean EPSP amplitude for the conditioned group and pseudorandom controls is shown in Figure $6 C$.

\section{Synaptic facilitation of $\mathrm{I}_{\mathbf{i}}$ monosynaptic IPSPs}

In a previous study of conditioning, we showed facilitation of the medial type A monosynaptic IPSP elicited by a single spike in the medial type B photoreceptor (Frysztak and Crow, 1994). Type I interneurons are directly excited or inhibited by action potentials generated in identified A or B photoreceptors (Crow and Tian, 2000, 2002). Therefore, CS-elicited changes in the complex IPSP may be the result of facilitation of type $I_{i}$ interneuron monosynaptic IPSPs. We examined the amplitude of monosynaptic IPSPs recorded from type $I_{i}$ interneurons elicited by single spikes in lateral type B photoreceptors from conditioned and pseudorandom control animals. The statistical analysis of the dark-adapted membrane potential of type $I_{i}$ interneurons revealed that there were no significant differences between conditioned groups $(\bar{X}=$ $50.4 \pm 1.04 \mathrm{mV})$ and pseudorandom controls $(\bar{X}=50.5 \pm 1.01$ $\mathrm{mV})\left(t_{59}=0.03\right.$; NS). Figure 7 shows representative examples of type $\mathrm{I}_{\mathrm{i}}$ interneuron IPSPs elicited by a single $\mathrm{B}$ photoreceptor spike from a conditioned animal (A2) and a pseudorandom control (B2). The membrane potential of type $\mathrm{I}_{\mathrm{i}}$ interneurons was held at $-60 \mathrm{mV}$ with the application of hyperpolarizing current. As shown in the two examples in Figure 7, conditioning resulted in a facilitation of the B spike-elicited monosynaptic IPSP in the $\mathrm{I}_{\mathrm{i}}$ interneuron relative to the pseudorandom control. The analysis of the group data for the amplitude of monosynaptic IPSPs from conditioned animals $(n=8)$ and pseudorandom controls $(n=9)$ revealed that conditioning produced a significant facilitation of IPSP amplitude $\left(t_{15}=3.1 ; p<0.007\right)$. As shown in the summary data in Figure $7 C$, mean IPSP amplitude was $7.8 \mathrm{mV}$ for type $\mathrm{I}_{\mathrm{i}}$ interneurons from the sample of conditioned animals and $4.5 \mathrm{mV}$ for IPSPs recorded from the pseudorandom controls.

\section{DISCUSSION}

\section{Overview}

Previous studies of Pavlovian conditioning of Hermissenda have identified several sites of plasticity involving modifications in excitability of identified type B and A photoreceptors. Voltageclamp experiments of type B photoreceptors isolated by axotomy after conditioning revealed that voltage $\left(I_{\mathrm{A}}, I_{\mathrm{Ca}}\right)$ and $\mathrm{Ca}^{2+}$. dependent $\left(I_{\mathrm{K}, \mathrm{Ca}}\right)$ currents are reduced (Alkon et al., 1982, 1985; Collin et al., 1988). Taken collectively, the net effect of modifications in the different intrinsic membrane conductances of type B photoreceptors could explain both the CS-elicited enhancement of the generator potential and CS-evoked increased spike activity detected after conditioning. Anatomical studies of type B photoreceptors indicate that there are three spatially segregated compartments (Eakin et al., 1967; Stensaas et al., 1969; Crow et al., 1979; Senft et al., 1982). Phototransduction occurs in the soma-rhabdomeric compartment, spike generation occurs in the distal axon, and synaptic interactions occur in the axon terminal regions within the cerebropleural neuropil (Alkon and Fuortes, 1972; Crow et al., 1979). Therefore, the decrease in $\mathrm{K}^{+}$conductances could contribute both directly and indirectly to enhanced excitability by increasing the amplitude of CS-elicited generator potentials and increasing CS-elicited spike activity in the spikegenerating zone by modification of conductances that influence the interspike interval. More recently, synaptic facilitation of the monosynaptic connection between type B and type A photoreceptors has been identified after Pavlovian conditioning (Frysztak and Crow, 1994, 1997; Gandhi and Matzel, 2000). Thus, Pavlovian conditioning of Hermissenda results in changes in both PSPs and cellular excitability in identified neurons of the CS pathway. 
A1

Conditioned $10 \mathrm{mV}$

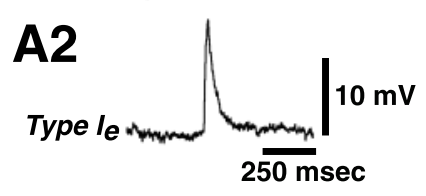

Figure 7. Conditioning results in facilitation of $\mathrm{I}_{\mathrm{i}}$ monosynaptic IPSPs. A single lateral B photoreceptor spike generated by an extrinsic current pulse (A1) elicited a monosynaptic IPSP recorded in a type $\mathrm{I}_{\mathrm{i}}$ interneuron $(A 2)$ from a conditioned animal. A single lateral B spike generated by a current pulse (B1) elicited a smaller IPSP recorded in a type $\mathrm{I}_{\mathrm{i}}$ interneuron $(B 2)$ from a pseudorandom control animal. $C$, Group data (means $\pm \mathrm{SEM}$ ) for the amplitude of type I interneuron IPSPs recorded from conditioned animals $(n=8)$ and pseudorandom controls $(n=9) .{ }^{*} p<0.007$.
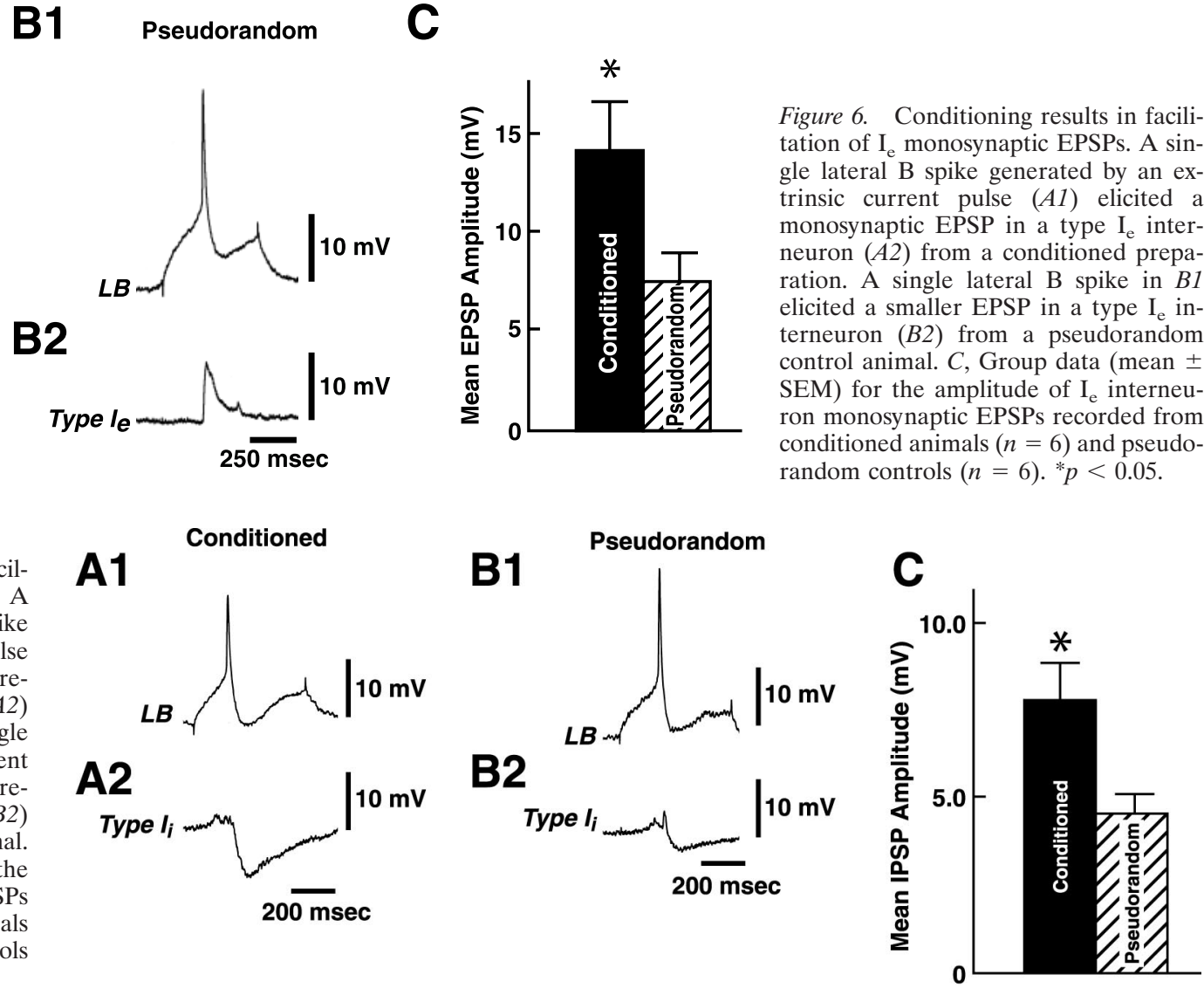

Figure 6. Conditioning results in facilitation of $\mathrm{I}_{\mathrm{e}}$ monosynaptic EPSPs. A single lateral B spike generated by an extrinsic current pulse (A1) elicited a monosynaptic EPSP in a type $\mathrm{I}_{\mathrm{e}}$ interneuron $(A 2)$ from a conditioned preparation. A single lateral $\mathrm{B}$ spike in $B 1$ elicited a smaller EPSP in a type $I_{e}$ interneuron (B2) from a pseudorandom control animal. $C$, Group data (mean \pm SEM) for the amplitude of $I_{e}$ interneuron monosynaptic EPSPs recorded from conditioned animals $(n=6)$ and pseudorandom controls $(n=6)$. ${ }^{*} p<0.05$.

\section{Synaptic facilitation}

Progress in the identification of neurons in the circuitry generating visually influenced mucociliary locomotion has provided additional sites for conditioning-dependent plasticity. We have identified two aggregates of interneurons: one receiving monosynaptic input from identified type A and B photoreceptors (type $I_{e}$ and $I_{i}$ ) and the other receiving polysynaptic input from identified photoreceptors (type $\mathrm{II}_{\mathrm{e}}$ and $\mathrm{II}_{\mathrm{i}}$ ) (Crow and Tian, 2000, 2002). Here we have shown that conditioning results in facilitation of monosynaptic EPSPs and IPSPs elicited by single spikes in lateral B photoreceptors and CS-evoked enhancement of the complex EPSP and IPSP in type $\mathrm{I}_{\mathrm{e}}$ and $\mathrm{I}_{\mathrm{i}}$ interneurons relative to pseudorandom controls. Our results suggest that the facilitation of monosynaptic EPSPs and IPSPs and the enhancement of complex EPSPs and IPSPs may be caused by a presynaptic source because there were no detectable differences between conditioned and pseudorandom controls with respect to either input resistance or membrane potential of type I interneurons. However, other exclusively postsynaptic mechanisms could contribute to facilitation of spike-elicited monosynaptic PSPs and CS-evoked complex PSPs (Chitwood et al., 2001).

The enhanced amplitude of complex IPSPs in conditioned animals produced a statistically significant decrease in the CSelicited spike activity of type $I_{i}$ interneurons relative to the pre-CS baseline. The analysis revealed that the CS-elicited complex IPSP was more than twice as effective in inhibiting spike activity in type $\mathrm{I}_{\mathrm{i}}$ interneurons as compared with pseudorandom controls (Fig. 4). In addition, our electrophysiological analysis revealed that the CS elicited significantly more spikes in type $I_{e}$ interneurons of conditioned animals relative to interneuron re-

cordings from pseudorandom controls. Consistent with the finding of an increase in CS-elicited spike frequency in $\mathrm{I}_{\mathrm{e}}$ interneurons with conditioning was our observation that complex EPSP amplitude was enhanced in conditioned animals. In addition, monosynaptic EPSPs in type $I_{e}$ interneurons elicited by single spikes in lateral $\mathrm{B}$ photoreceptors exhibited synaptic facilitation. However, the dark-adapted resting membrane potential and input resistance of type I interneurons were not modified by conditioning. Taken collectively, the results would be consistent with the hypothesis that enhancement of complex PSP amplitude detected in conditioned animals may be produced by both facilitation of monosynaptic PSPs and CS-elicited increases in spike activity in identified photoreceptors that are presynaptic to type $I_{e}$ and $I_{i}$ interneurons.

\section{General role of interneurons in behavioral plasticity}

The cellular and synaptic analysis of Pavlovian conditioning in Hermissenda indicates that the neural circuitry supporting conditioning is much more complex than envisioned initially (Goh and Alkon, 1984; Goh et al., 1985). It has now been shown that several identified sites in the pathway supporting the CS express both synaptic plasticity and intrinsic changes in cellular excitability. Conditioning results in an enhancement of the CS-elicited generator potential, enhancement of type A and B spike activity elicited by the CS and extrinsic current, facilitation of the B spike monosynaptic IPSP in type A photoreceptors, and facilitation of monosynaptic PSPs in type I interneurons. These results suggest that a cellular and synaptic analysis at a neural systems level will be required to produce a reasonably complete description of the neural basis for the generation of conditioned behavior. Because 
there are no direct synaptic connections between photoreceptors and pedal motor neurons supporting locomotion (Crow et al., 1979), the contribution of type I and type II interneurons and their postsynaptic targets to light-elicited locomotion may be essential in understanding how conditioning is expressed in behavior.

Work with other invertebrate species has identified interneurons as important sites of plasticity. For example, olfactory learning and olfactory discrimination in Limax involve a network of olfactory interneurons (Kleinfeld et al., 1994; Gelperin and Flores, 1997; Ermentrout et al., 2001). In Aplysia, interneurons have been implicated as sites of plasticity in habituation and sensitization, examples of non-associative learning (Cleary et al., 1995). Moreover, intrinsic changes in excitability of an interneuron ( $\mathrm{S}$ cell) in the leech have been detected during nonassociative learning of the shortening reflex (Burrell et al., 2001), and Retzius cells express a correlate of CS-US predictability (Sahley and Crow, 1998). In addition, modifications in interneurons in the feeding circuit of Lymnaea have been identified after conditioning (for review, see Benjamin et al., 2000).

The results of the present report and previously identified sites of plasticity in the CS pathway suggest that changes in both excitability and synaptic strength may occur at multiple loci within components of the neural circuit supporting conditioning. Our investigation of conditioning in Hermissenda will now focus on postsynaptic targets of type $\mathrm{I}_{\mathrm{e}}$ and $\mathrm{I}_{\mathrm{i}}$ interneurons.

\section{REFERENCES}

Akaike T, Alkon DL (1980) Sensory convergence on central visual neurons in Hermissenda. J Neurophysiol 44:501-513.

Alkon DL, Fuortes MGF (1972) Responses of photoreceptors in Hermissenda. J Gen Physiol 60:631-649.

Alkon DL, Lederhendler I, Shoukimas JJ (1982) Primary changes of membrane currents during retention of associative learning. Science 215:693-695.

Alkon DL, Sakakibara M, Forman R, Harrigan J, Lederhendler I, Farley $\mathrm{J}$ (1985) Reduction of two voltage-dependent $\mathrm{K}^{+}$currents mediates retention of a learned association. Behav Neurol Biol 44:278-300.

Beggs TM, Brown TH, Byrne JH, Crow T, LeDoux JE, Thompson RF (1999) Learning and memory: basic mechanisms and systems. In: Fundamental neuroscience (Bloom F, Landis S, Roberts J, Squire L, Zigmond M, eds), pp 1411-1454. San Diego: Academic.

Benjamin PR, Stanas K, Kemones G (2000) A systems approach to the cellular analysis of associative learning in the Lymnaea. Learn Mem 7:124-131.

Burrell BD, Sahley CL, Muller KJ (2001) Non-associative learning and serotonin induce similar bi-directional change in excitability of a neuron critical for learning in the medicinal leech. J Neurosci 24:1401-1412.

Chitwood RA, Li Q, Glanzman DL (2001) Serotonin facilitation AMPA-type responses in isolated siphon motor neurons of Aplysia in culture. J Physiol (Lond) 534 2:501-510.

Cleary LJ, Byrne JH, Frost WN (1995) Role of interneurons in defensive withdrawal reflexes in Aplysia. Learn Mem 2:133-151.

Collin CC, Ikeno H, Harrigan JF, Lederhendler I, Alkon DL (1988) Sequential modifications of membrane currents with classical conditioning. Biophys J 54:955-960.

Crow T (1985) Conditioned modification of phototactic behavior in Hermissenda. II. Differential adaptation of B-photoreceptors. J Neurosci 5:215-223.

Crow T (1988) Cellular and molecular analysis of associative learning and memory in Hermissenda. Trends Neurosci 11:136-142.

Crow T, Alkon DL (1978) Retention of an associative behavioral change in Hermissenda. Science 201:1239-1241.

Crow T, Alkon DL (1980) Associative behavioral modification in Hermissenda: cellular correlates. Science 209:412-414.

Crow T, Offenbach N (1983) Modification of the initiation of locomotion in Hermissenda: behavioral analysis. Brain Res 271:301-310.

Crow T, Tian L-M (2000) Monosynaptic connections between identified type $\mathrm{A}$ and $\mathrm{B}$ photoreceptors and interneurons in Hermissenda. J Neurophysiol 84:367-375.

Crow T, Tian L-M (2002) Morphological characteristics and central projections of two types of interneurons in the visual pathway of Hermissenda. J Neurophysiol 87:322-332.

Crow T, Heldman E, Hacopian V, Enos R, Alkon DL (1979) Ultrastructure of photoreceptors in the eye of Hermissenda labeled with intracellular injection of horseradish peroxidase. J Neurocytol 8:181-195.
Crow T, Forrester J, Williams M, Waxham MN, Neary JT (1991) Downregulation of protein kinase $\mathrm{C}$ blocks 5 -HT-induced enhancement in Hermissenda B-photoreceptors. Neurosci Lett 12:107-110.

Crow T, Xue-Bian JJ, Siddiqi V, Kang Y, Neary JT (1998) Phosphorylation of mitogen-activated protein kinase by one-trial and multi-trial classical conditioning. J Neurosci 18:3480-3487.

Disterhoft JF, Coulter DA, Alkon DL (1986) Conditioning-specific membrane changes of rabbit hippocampal neurons measured in vitro. Proc Natl Acad Sci USA 83:2733-2737.

Eakin RM, Westfall JA, Dennis MJ (1967) Fine structure of the eye at a nudibranch mollusk Hermissenda crassicornis. J Cell Soc 2:349-358.

Ermentrout B, Wang JW, Flores J, Gelperin A (2001) Model for olfactory discrimination and learning in Limax procerebrum incorporating oscillatory dynamics and wave propagation. J Neurophysiol 85:144-1452.

Farley J, Alkon DL (1982) Associative neural and behavioral change in Hermissenda: consequences of nervous system orientation for light- and pairing-specificity. J Neurophysiol 48:785-807.

Farley J, Auerbach S (1986) Protein kinase C activation induces conductance changes in Hermissenda photoreceptors like those seen in associative learning. Nature 319:220-223.

Farley J, Schuman E (1991) Protein kinase C inhibitors prevent induction and continued expression of cell memory in Hermissenda type B photoreceptors. Proc Natl Acad Sci USA 88:2016-2020.

Frysztak RJ, Crow T (1993) Differential expression of correlates of classical conditioning in identified medial and lateral type A photoreceptors of Hermissenda. J Neurosci 13:2889-2897.

Frysztak RJ, Crow T (1994) Enhancement of type B- and type A-photoreceptor inhibitory connections in conditioned Hermissenda. J Neurosci 14:1245-1250.

Frysztak RJ, Crow T (1997) Synaptic enhancement and enhanced excitability in presynaptic and postsynaptic neurons in the conditioned stimulus pathway of Hermissenda. J Neurosci 17:4426-4433.

Gandhi CL, Matzel LD (2000) Modulation of presynaptic action potential kinetics underlies synaptic facilitation of type B photoreceptors after associative conditioning in Hermissenda. J Neurophysiol 20:2022-2035.

Gelperin A, Flores J (1997) Vital staining from dye-coated microprobes identifies new olfactory interneurons for optical and electrical recording. J Neurosci Methods 72:97-108.

Goh Y, Alkon DL (1984) Sensory, interneuronal, and motor interactions within Hermissenda visual pathway. J Neurophysiol 52:156-168.

Goh Y, Lederhendler I, Alkon DL (1985) Input and output changes of an identified neural pathway are correlated with associative learning in Hermissenda. J Neurosci 5:536-543.

Kleinfeld D, Delaney KR, Fee MS, Flores JA, Tank DW, Gelperin A (1994) Dynamics of propagating waves in the olfactory network of a terrestrial mollusk: an electrical and optical study. J Neurophysiol 72:1402-1419.

Lederhendler I, Gart S, Alkon DL (1986) Classical conditioning of Hermissenda: origin of a new response. J Neurosci 6:1325-1331.

Matzel LD, Lederhendler II, Alkon DL (1990) Regulation of short-term associative memory by calcium-dependent protein kinase. J Neurosci 10:2300-2307.

Moyer JR, Thompson LT, Disterhoft JF (1996) Trace eyeblink conditioning increases CA1 excitability in a transient and learning-specific manner. J Neurosci 16:5536-5546.

Muzzio IA, Gandhi CC, Manyam U, Pesnell A, Matzel LD (2001) Receptor-stimulated phospholipase $\mathrm{A}_{2}$ liberates arachidonic acid and regulates neuronal excitability through protein kinase C. J Neurophysiol 85:1639-1647.

Sahley C, Crow T (1998). Invertebrates learning: current perspectives. In: Neurobiology of learning and memory (Martinez J, Kesner R, eds), pp 171-209. New York: Academic.

Schultz LM, Clark GA (1995) GABA-induced facilitation at type B to A photoreceptor synapses in Hermissenda. Soc Neurosci Abstr 21:1679.

Schuman EM, Clark GA (1994) Synaptic facilitation at connections of Hermissenda type B-photoreceptors. J Neurosci 14:1613-1622.

Senft SL, Allen RD, Crow T, Alkon DL (1982) Optical sectioning of HRP-stained molluscan neurons. J Neurosci Methods 5:153-159.

Stensaas LJ, Stensaas SS, Trujillo-Cenoz O (1969) Some morphological aspects of the visual system of Hermissenda crassicornis (mollusca: nudibranchia). J Ultrastruct Res 27:510-532.

Thompson LT, Moyer JR, Disterhoft JF (1996) Transient changes in excitability of rabbit CA3 neurons with a time-course appropriate to support memory consolidation. J Neurophysiol 70:1210-1220.

West A, Barnes ES, Alkon DL (1982) Primary changes of voltage responses during retention of associative learning. J Neurophysiol 48:1243-1255.

Woody CD, Engel Jr J (1972) Changes in unit activity and thresholds to electrical stimulation of coronal-pericruciate cortex of cat with classical conditioning of different facial movements. J Neurophysiol 35:230-241.

Woody CD, Knispel JD, Crow TJ, Black-Cleworth PA (1976) Activity and excitability to electrical current of cortical auditory receptive neurons of awake cats as affected by stimulus association. J Neurophysiol 39:1045-1061. 